\title{
Identifying Relative Weights of Evaluation Indices for Library Website Usability Acceptance Model by Applying the Extent Analysis Fuzzy AHP Approach
}

Kokila Harshan Ramanayaka, Xianqiao Chen, Bing Shi

Wuhan University of Technology

China

3350425205@qq.com

chenxq@whut.edu.cn

744047249@qq.com

\begin{abstract}
A library website plays an enhanced role compared to its traditional physical library while providing a wide variety of library services to its users. Evaluation of library websites is a key to realize the extent of user acceptance to the website and to improve overall quality of website. Usability is a highly recognized factor to determine how easy to use the website. The models of usability evaluations evaluate the ease of use of website operations and see whether the users can perform their tasks easily. Moving on further, this study has been undertaken in context of library websites in Sri Lanka with the main purpose of exploring the favourable weights of the seven key dimensions and 20 measuring items with the aids of experts in the related field. These dimensions and measuring items were identified from our previous study which have been tested its reliability and validity in assessing library website usability in Sri Lanka with the aids of actual library users in Sri Lanka. Fuzzy theories together with the extent analysis fuzzy analytic hierarchy process method were applied. It was expected to identify the relative importance of the criteria of interest while avoiding uncertainty, ambiguity, loss of data, and difficulties faced in assessment cycle. Triangular fuzzy numbers were used to represent the judgments on the relative importance between each pair of factors that makes experts consensus uniform rather than using linguistic values. The research findings concluded that satisfaction was the dimension that the experts considered most important in evaluating library website usability. The experts rated accessibility as the least important dimension.
\end{abstract}

Keywords: Library Website Evaluation, Fuzzy AHP, Usability Evaluation, Website Usability

Received: 11 May 2018, Revised 20 June 2018, Accepted 28 June 2018

DOI: $10.6025 /$ ijwa/2018/10/4/137-153

(C) 2018 DLINE. All Rights Reserved

\section{Introduction}

With the rapid development of internet technology and information technology, website of an organization has taken an important place as a virtual image and a public interface for information seekers around the world. Website is regarded as a global gateway to enter the knowledge repositories and achieve required services. Thus the websites have been identified as an easiest and effective way of distributing information and procuring services to its clients. In addition, greater research impact, attracting visitors and serving services on time are the benefits which can be gained from of an effective website [1]. Therefore, according

International Journal of Web Applications Volume 10 Number 4 December 2018 
to the fast changing environment of the technology, organizations need to develop instructive and rich websites with continuous monitoring and updating mechanisms[2].

Today, website is considered as a lifeline of libraries worldwide. Websites are mainly used as a virtual image and promotional platform of the library that displays information and services of a library. Presently, libraries draw attention to promote eresources, online catalogues, web 2.0 services, and online reference services through their websites. By providing the said services they expect to achieve the existing challenges of promoting better visibility for their print resources, offering various value added electronic services, and providing an access to quality content in electronic form. In addition, user satisfaction to the website is another big demand for the libraries. User satisfaction can be achieved if the interface and content of the library website have fulfilled with the usability principles [3]. Therefore, developing usable websites so as to meet the demands of information and services is essential for library's success since users touch, feel, search, and experience information and services that provide mainly through websites [4]. Usability is considered as the most important item of the website while it measures the simplicity of the website [5]. In the recent years, usability evaluations, especially, in commercial websites have been conducted to diagnose problems of current websites and to enhance website interfaces by better reflecting user viewpoints. As a result of usability evaluation, a positive attitude to the website and revisit rates can be increased effectively. On the other hand, it supports to reduce website development, maintenance, and support costs as well [6]. Because of each website has different kind of features and different categories of user requirements, the usability measuring criteria used for evaluating the websites may be different [7]. However, there is a lack of consensus on the construct of website usability and how to measure them. Thus different set of website usability dimensions with different important levels were taken to measure the usability in specific type of websites in previous studies [4]. Nevertheless, there are no sufficient researches conducted in library websites usability evaluations. In the literature review, it has been found that no any specific research studies conducted related to university or other type of library website usability evaluation in Sri Lanka country context.

In this backdrop, we have identified a major measurement instrument dimensions and their measurement items for usability evaluation specific to a library websites in Sri Lanka which were validated its reliability and validity from our previous study. The final usability evaluation model consisted of the seven dimensions and two to three measurement items for each dimension as shown in Table 1. Subsequently, it is essential to ascertain and prioritize relative weights of the key dimensions and measuring items to ensure successful implementation of library website usability index system. Therefore, the main purpose of this paper is to assess the key dimensions and measuring items weights of a library website usability evaluation index system through the extent analysis fuzzy analytic hierarchy process method.

The remainder of this paper is organized as follows. Section 2 reviews the prior research related to the topic.

Section 3 describes preliminaries including fuzzy theory with fundamental fuzzy number operations related to concepts. The methodology that referred to determine relative weights of the key dimensions and measuring items for library website usability index system describes in section 4. Section 5 deals with factors determining the key dimensions and measuring items weights for library website usability acceptance model. Section 6 provides an account of findings and means of applications. The paper is concluded with avenues for future research in section 7.

\section{Related Previous Works}

It can be seen that the Multiple Criteria Decision Making (MCDM) techniques were applied by many researchers to find out the weights of criteria in different disciplines. The linear weighting methods (LW), Mathematical Programming (MP) techniques, the Analytic Network Process (ANP), the Analytic Hierarchy Process (AHP), and Fuzzy AHP (FAHP) are the leading MCDM problem solving techniques used in prior researches. Herein, LW that accommodates equal weights for each measuring attributes considered as a simple MCDM method. On the other hand, significant problems arise when handling qualitative criteria in MP techniques while AHP is considered as an ineffective tool because of the inherent imprecision and uncertainty connected with the mapping of a decision maker's assessment to exact numbers. ANP can be used to solve MCDM problems wherein the criteria affect each other and have nonlinear correlation. The fuzzy based AHP approach is a more effective solution to solve MCDM related problems because it's powerful ability to deal with imprecise and uncertain data. Further, it support to decision makers to assign linguistic variables in the form of numeric values to express their judgments and there has a possibility to incorporate the incomplete, unobtainable and unquantifiable information into the decision model in fuzzy environment [8-11].

$138 \quad$ International Journal of Web Applications Volume 10 Number 4 December 2018 
Thus, it can be seen that FAHP methods has been widely applied to solve different MCDM related problems. For example, studies by Chen, Hsieh and Do [11] have determined the factors and sub-factors weights of teaching performance evaluation system applying the extent analysis FAHP method; Mikhailov and Tsvetinov [12] have proposed FAHP based ranking service offers model by addressing the problem of uncertainty and imprecision; Gungor et al. [13] have designed a MCDM model to select the most adequate person for the job adopting FAHP approach and Yager's weighted method to determine the criteria weights; Chou et al. [14] have developed a framework for evaluate the performance of science and technology human resources using Evaluation Laboratory (DEMATEL) and fuzzy Decision-making Trial methods. This framework has employed FAHP to obtain the criteria weights; Taylana et al. [15] have applied FAHP to find the favorable weights of the key risk criteria for the construction projects evaluation; Sadeghi, Moghimi and Ramezan [16] have applied FAHP to find the weights of each factor affected on knowledge management execution readiness; Mehralian et al. [17] have ranked and prioritized critical success factors that affect total quality management in the pharmaceutical industry adopting fuzzy TOPSIS technique; Moghimi and Jusan [18] have applied non-structural FAHP method to determine housing preference decision criteria weights; Liu et al. [19] have conducted a study to determine weights of evaluation factors for e-commerce websites ranking using FAHP techniques; Nagpal et al. [7] used the extent analysis fuzzy AHP method to obtain the criteria and sub-criteria weights while developing a website ranking system based on Fuzzy TOPSIS method; By using the extent analysis fuzzy AHP method, Atalay and Eraslan [20] have examined the criteria weights for usability evaluation of MP3 players.

Furthermore, some studies have been used other MCDM methods to examine the criteria importance in real-life decision-making problem solving. For example, studies by Pearson, Pearson and Green [21] have applied linear regressions, MCDM approach and Tukey's honestly significant differences methods to investigate the relative importance of five website usability criteria; A study done by Calisir et al. [22] have analysed the relative importance of the online auction and shopping website usability criteria using the ANP method; Kamal and Alsudairi [23] have investigated the integration technologies factor importance in local government authorities through AHP technique; By using AHP, Roy, Pattnaik and Mall [24] have examined the factor weights for evaluation of quality assurance of academic websites. In summary, FAHP methods are suited to determine the criteria weights of the evaluation systems efficiently and effectively due to its highly applicability for solve MCDM problems.

\section{Preliminaries}

\subsection{Fuzzy Sets and Fuzzy Numbers}

Fuzzy set theory was developed by Professor Zadeh in 1965, that transforms conceptual language into a mathematic form to explain human behavioural fuzziness by a set of values with more flexible and better expresses human thinking when it is applied to decision making problems [25-26]. Van Laarhoven and Pedrycz [27] initially introduced the FAHP with employing the Trangular Fuzzy Number (TFN) to represent a pair-wise comparison ratio in AHP. Buckley [28] has initially applied fuzzy set theory for improvements of the traditional AHP with introducing fuzzy ratios into the pair-wise comparisons. The FAHP replaces the exact values of the AHP with interval values, which enables to evaluate problems in a more human scale and provides correlative values for evaluation factors [26]. Because the FAHP have saturated with a systematic methods to handle incomplete information also, decision makers can use FAHP for comparison and weighting of the criteria and alternatives easily with incomplete information. According to Dominic and Khan [29], the fuzzy algorithms that use fuzzy logic and fuzzy sets, which are the most useful mathematical tools for modelling, is one of the main approaches to evaluate the MCDM problems.

A fuzzy number can be described by a given interval between 0 and 1 of real numbers [30] and a triangular fuzzy number is a distinctive category of fuzzy number including three real numbers $(l, m, u)$ [31]. Let $x$ be a fuzzy number, then the membership function can be illustrated as:

$$
\mu_{\mathrm{A}}(\mathrm{x})=\left\{\begin{array}{cc}
(\mathrm{x}-\mathrm{l}) /(\mathrm{m}-\mathrm{l}) & \mathrm{l} \ll \mathrm{x} \ll \mathrm{m} \\
(\mathrm{u}-\mathrm{x}) /(\mathrm{u}-\mathrm{m}) & \mathrm{m} \ll \mathrm{x} \ll \mathrm{u} \\
0 & \text { otherwise }
\end{array}\right.
$$

where $m$ is the most potential value of fuzzy number $A$, and $l$ and $u$ are the lower and upper bounds of the fuzziness of the data evaluated, respectively. 


\begin{tabular}{|c|c|c|}
\hline Level 1: Goal & Level 2: Dimensions & Level 3: measuring items \\
\hline \multirow{17}{*}{$\begin{array}{l}\text { Calculating the weights of } \\
\text { all key dimensions and } \\
\text { measuring items for library } \\
\text { website usability index } \\
\text { system }\end{array}$} & \multirow[t]{3}{*}{ Accessibility $\left(D_{1}\right)$} & Pages loading speed on this site is acceptable $\left(D_{11}\right)$ \\
\hline & & Visual appeal of the site is satisfying $\left(D_{12}\right)$ \\
\hline & & Site is in online every time $\left(\mathrm{D}_{13}\right)$ \\
\hline & \multirow[t]{2}{*}{ Content $\left(\mathrm{D}_{2}\right)$} & $\begin{array}{l}\text { There is an archive of previously published materials or ar- } \\
\text { ticles }\left(D_{21}\right)\end{array}$ \\
\hline & & $\begin{array}{l}\text { The textual content and illustrations are up-to-date }\left(\mathrm{D}_{22}\right) \\
\text { Ads \& pop-ups are not apparent }\left(\mathrm{D}_{23}\right)\end{array}$ \\
\hline & \multirow[t]{2}{*}{ Efficiency $\left(\mathrm{D}_{3}\right)$} & The website is well organized to find what I want $\left(D_{31}\right)$ \\
\hline & & $\begin{array}{l}\text { I can quickly complete a resource-finding task without any } \\
\text { difficulties } \\
\left(D_{32}\right)\end{array}$ \\
\hline & \multirow[t]{3}{*}{ Learnability $\left(\mathrm{D}_{4}\right)$} & $\begin{array}{l}\text { The terminologies used on this library website were easily } \\
\text { understandable }\left(D_{41}\right)\end{array}$ \\
\hline & & It was easy to learn to use this library $\left(\mathrm{D}_{42}\right)$ \\
\hline & & $\begin{array}{l}\text { This library website provides appropriate help functions } \\
\text { and information }\left(\mathrm{D}_{43}\right)\end{array}$ \\
\hline & \multirow[t]{3}{*}{ Navigation $\left(\mathrm{D}_{5}\right)$} & $\begin{array}{l}\text { The current location is clearly indicated in each web pages } \\
\left(D_{51}\right)\end{array}$ \\
\hline & & $\begin{array}{l}\text { The Home page has included links to access all major parts of } \\
\text { the site }\left(\mathrm{D}_{52}\right)\end{array}$ \\
\hline & & $\begin{array}{l}\text { Structure of the website looks simple without any unneces- } \\
\text { sary levels }\left(D_{53}\right)\end{array}$ \\
\hline & \multirow[t]{3}{*}{ Satisfaction $\left(\mathrm{D}_{6}\right)$} & $\begin{array}{l}\text { I like to recommend this site to my colleagues for getting infor- } \\
\text { mation }\left(D_{61}\right)\end{array}$ \\
\hline & & I am satisfied with this library overall $\left(D_{62}\right)$ \\
\hline & & $\begin{array}{l}\text { It is a pleasure to use this library website to find what I want } \\
\left(D_{63}\right)\end{array}$ \\
\hline & Usefulness $\left(\mathrm{D}_{7}\right)$ & $\begin{array}{l}\text { Accuracy of information on this site is satisfying }\left(D_{71}\right) \\
\text { Quality of information on this site is acceptable }\left(D_{72}\right) \\
\text { E-reference sources provided through the site are satisfying } \\
\left(D_{73}\right)\end{array}$ \\
\hline
\end{tabular}

Table 1. The hierarchical structure of key dimensions and measuring items for library website usability index system 


\subsection{Algebraic Operations in Fuzzy Theory}

Let two positive triangular fuzzy numbers namely, $A=\left(l_{1}, m_{1}, u_{1}\right)$ and $B=\left(l_{2}, m_{2}, u_{2}\right)$. The basic fuzzy arithmetic operations on these fuzzy numbers can be defined as [30]:

a) Inverse $A^{-1}=\left(\frac{1}{u_{1}}, \frac{1}{m_{1}}, \frac{1}{l_{1}}\right)$

b) Addition $A+B=\left(l_{1}+l_{2}, m_{1}+m_{2}, u_{1}+u_{2}\right)$

c) Subtraction $A-B=\left(l_{1}-u_{2}, m_{1}-m_{2}, u_{1}-u_{2}\right)$

d) Scalar Multiplication $\begin{aligned} & \forall k>0, k \in R, k A=\left(k l_{1}, k m_{1}, k u_{1}\right) \\ & \forall k<0, k \in R, k A=\left(k u_{1}, k m_{1}, k l_{1}\right)\end{aligned}$

e) Multiplication $A B=\left(l_{1} l_{2}, m_{1} m_{2}, u_{1} u_{2}\right)$

f) Division $\frac{A}{B}=\left(\frac{l_{1}}{u_{2}}, \frac{m_{1}}{m_{2}}, \frac{u_{1}}{l_{2}}\right)$

\subsection{Linguistic Variables and Fuzzy Conversion Scale}

A linguistic variable is a variable whose values represent from words or sentences in a natural or artificial language while it can be easily applied in such situation that are complicated and hard to define [32]. The corresponding linguistic scales for rating the pair-wise comparisons of dimensions importance level on a qualitative scale are defined as, "just equal", "equally important", "moderately more important", "strongly more important", "very strongly more important" and "extremely more important". Then the linguistic scales are converted into fuzzy numbers using the triangular fuzzy conversion scale ranging from 1 to 7 according to the Figure 1 and Table 2 [33].

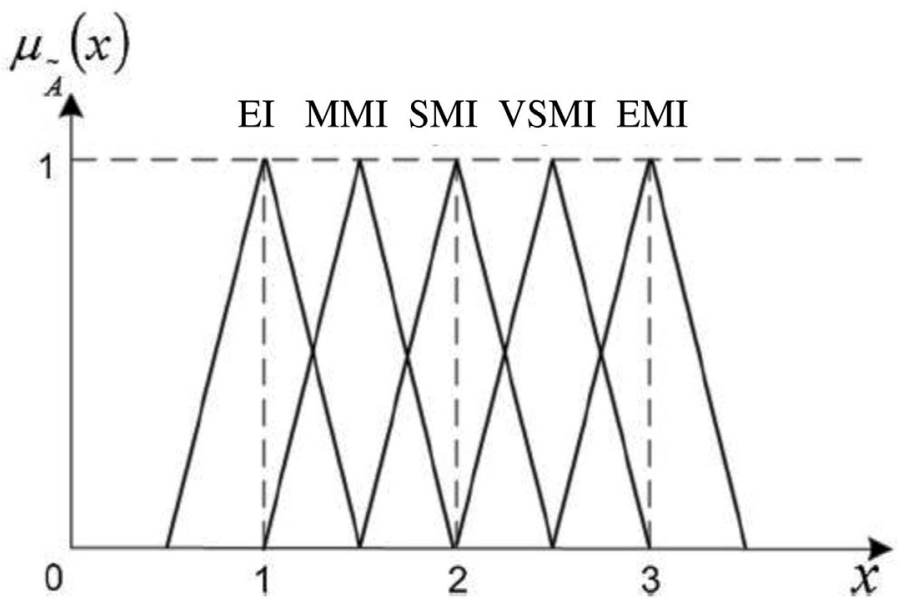

Figure 1. Linguistic scale for relative importance

\section{Methodology}

The main objective of this study is to determine relative weightings of the key dimensions and measuring items to ensure successful implementation of library website usability index system. For that, Chang's extent analysis fuzzy AHP method [34] was employed because of its highly applicability such type of evaluations.

\subsection{Developing the Hierarchical Structure}

The hierarchical structure of the problem can be drawn by combining all the key dimensions and measuring items that affect to 
the library website usability specific to the research problem.

\subsection{Establishing a Group of Experts in the Field}

A committee of experts in the related field was formed to determine the relative importance of key dimensions and measuring items. The experts have expressed relative importance between each pair of factors verbally as just equal, equally important, moderately more important, strongly more important, very strongly more important and extremely more important which are in the form of linguistic variables with the help of questionnaires.

\begin{tabular}{|l|c|c|}
\hline $\begin{array}{l}\text { Linguistic scale for } \\
\text { importance }\end{array}$ & $\begin{array}{c}\text { Triangular } \\
\text { fuzzy scale }\end{array}$ & $\begin{array}{c}\text { Triangular fuzzy } \\
\text { reciprocal scale }\end{array}$ \\
\hline Just Equal (JE) & $(1,1,1)$ & $(1,1,1)$ \\
\hline $\begin{array}{l}\text { Equally Important } \\
\text { (EI) }\end{array}$ & $(1 / 2,1,3 / 2)$ & $(2 / 3,1,2)$ \\
\hline $\begin{array}{l}\text { Moderately More } \\
\text { Important (MMI) }\end{array}$ & $(1,3 / 2,2)$ & $(1 / 2,2 / 3,1)$ \\
\hline $\begin{array}{l}\text { Strongly More } \\
\text { Important (SMI) }\end{array}$ & $(3 / 2,2,5 / 2)$ & $(2 / 5,1 / 2,2 / 3)$ \\
\hline $\begin{array}{l}\text { Very Strongly More } \\
\text { Important(VSMI) }\end{array}$ & $(2,5 / 2,3)$ & $(1 / 3,2 / 5,1 / 2)$ \\
\hline $\begin{array}{l}\text { Extremely More } \\
\text { Important (EMI) }\end{array}$ & $(5 / 2,3,7 / 2)$ & $(2 / 7,1 / 3,2 / 5)$ \\
\hline
\end{tabular}

Table 2. Linguistic scales and fuzzy scales for importance

\subsection{Establishing Comparison Matrices}

The descriptive judgments which are in the form of linguistic variables are then translated into the triangular fuzzy scale as defined in Table II to construct the comparison matrix of each level with $n$ factors, $\widetilde{\mathrm{A}}=\left\{\tilde{\mathrm{a}}_{\mathrm{ij}}\right\}$ that represents the relative importance of factor $i$ to $j$. For example, if the decision maker expressed that the factor $i$ is very strongly more important when compared with factor $j$, then $\widetilde{\mathrm{a}_{\mathrm{ij}}}=(2,5 / 2,3)$, otherwise $\widetilde{\mathrm{a}_{\mathrm{ij}}}=(1 / 3,2 / 5,1 / 2)$. Herein, $n(n-1) / 2$ pair-wise comparison judgments required at a level with $\mathrm{n}$ elements for construct the comparison matrix and the comparison matrices need to be constructed for main level factors and sub-level factors in each main level factors.

$$
\tilde{A}=\left[\begin{array}{cccc}
1 & \tilde{a}_{12} & \cdots & \tilde{a}_{1 n} \\
\tilde{a}_{21} & 1 & \cdots & \tilde{a}_{2 n} \\
\vdots & \vdots & \ddots & \vdots \\
\tilde{a}_{n 1} & \tilde{a}_{n 2} & \cdots & 1
\end{array}\right]=\left[\begin{array}{cccc}
1 & \tilde{a}_{12} & \cdots & \tilde{a}_{1 n} \\
1 / \tilde{a}_{12} & 1 & \cdots & \tilde{a}_{2 n} \\
\vdots & \vdots & \ddots & \vdots \\
1 / \tilde{a}_{1 n} & 1 / \tilde{a}_{2 n} & \cdots & 1
\end{array}\right]
$$

\subsection{Calculating the Consistency Index and Consistency Ratio of Comparison Matrix}

The consistency of an evaluation needs to be analysis to confirm whether the expert decisions were in a certain quality level before processing ahead. Saaty [35] has proposed a index method to measure the crisp pair-wise comparison matrices consistency level. So, the fuzzy comparison matrices need to be transformed into crisp matrices using any defuzzification method [11].

\subsection{Construct Crisp Performance Matrix}

The defuzzification methods have a capability to convert the triangular fuzzy number into a crisp number effectively. So in this study, the authors decided to use the defuzzification method proposed by Chang, Wu and Lin [8] that use the decision maker's 
degree of confidence $(\alpha)$ regarding criteria weights and risk tolerance $(\lambda)$ of decision-makers for convert fuzzy comparison matrix into crisp matrix.

Herein, the value of $\alpha$ may be in between 0 and 1, and it will help to evade the complicated and unreliable practices [36]. A larger a value represents decision maker's assessments are more confident and closer to the most possible value, i.e. $m$, of the triangular fuzzy numbers $(l, m, u)$. In practical applications, $\alpha=1 ; \alpha=0.5$, and $\alpha=0$ are used to indicate that the decision maker involvement is in an optimistic, moderate, or pessimistic view, respectively [30,37]. Additionally, $\lambda$ can be considered as the degree of a decision maker's optimism and its range is also between 0 and 1 . The attitude of the decision maker can be positive, moderate or negative and accordingly they will have higher, average and less values for their fuzzy assessments. In practical applications, $\lambda$ $=1, \lambda=0.5$ and $\lambda=0$ are used to indicate optimistic, moderate, or pessimistic view respectively [7].

In order to aforesaid information, a triangular fuzzy number $\left(\widetilde{\mathrm{a}_{\mathrm{ij}}}=\left(\mathrm{l}_{\mathrm{ij}}, \mathrm{m}_{\mathrm{ij}}, \mathrm{u}_{\mathrm{ij}}\right)\right)$ can be defuzzified to a crisp number as follows.

$$
\left(\mathrm{a}_{\mathrm{ij}}^{\alpha}\right)^{\lambda}=\left[\lambda * \mathrm{l}_{\mathrm{ij}}^{\alpha}+(1-\lambda) * \mathrm{u}_{\mathrm{ij}}^{\alpha}\right], 0 \leq \lambda \leq 1,0 \leq \alpha \leq 1
$$

Here, $\mathrm{l}_{\mathrm{ij}}^{\alpha}=\left(\mathrm{m}_{\mathrm{ij}}-\mathrm{l}_{\mathrm{ij}}\right) * \alpha+\mathrm{l}_{\mathrm{ij}}$ represents the left end value of $\alpha$-cut for $a_{i j}$, and $\mathrm{u}_{\mathrm{ij}}^{\alpha}=\mathrm{u}_{\mathrm{ij}}-\left(\mathrm{u}_{\mathrm{ij}}-\mathrm{m}_{\mathrm{ij}}\right) * \alpha$ represents the right end value of $\alpha$-cut for $a_{i j}$.

Then the crisp performance matrix can be expressed from the crisp numbers as follows:

$$
\left[\left(\mathrm{A}^{\alpha}\right)^{\lambda}\right]=\left[\left(\mathrm{a}_{\mathrm{ij}}\right)^{\lambda}\right]=\left[\begin{array}{cccc}
1 & \left(\mathrm{a}_{12}^{\alpha}\right)^{\lambda} & \cdots & \left(\mathrm{a}_{1 \mathrm{n}}^{\alpha}\right)^{\lambda} \\
\left(\mathrm{a}_{21}^{\alpha}\right)^{\lambda} & 1 & \cdots & \left(\mathrm{a}_{2 \mathrm{n}}^{\alpha}\right)^{\lambda} \\
\vdots & \vdots & \ddots & \vdots \\
\left(\mathrm{a}_{\mathrm{n} 1}^{\alpha}\right)^{\lambda} & \left(\mathrm{a}_{\mathrm{n} 2}^{\alpha}\right)^{\lambda} & \cdots & 1
\end{array}\right]
$$

\subsection{Calculate Largest Eigen Value of the Crisp Performance Matrix $\left(\lambda_{\max }\right)$}

The largest eigen value of the crisp performance matrix was calculated using the following scheme:

- Calculate the sum of each column of the crisp performance matrix

- Divide each element of the crisp performance matrix with the sum of its column

- Take averaging values across the rows

- Calculate the sum of product of the sum of each column and averaging values across the rows

\subsection{Calculate the Consistence Index (CI)}

The Consistence Index (CI) for each comparison matrix can be calculated as follows:

$$
C I=\frac{\lambda_{\max }-n}{n-1}
$$

where $\lambda_{\max }$ is the largest eigen value of the crisp performance matrix and $n$ is the dimension of the matrix.

\subsection{Calculate the Consistency Ratio (CR)}

The Consistency Ratio (CR) can be computed by dividing the consistency index from the consistency of a random matrix [35] asfollows.

$$
C R=\frac{C I}{R I(n)}
$$

where $R I(n)$ is a random consistency index and its value is depended on the size on matrix as follows [35]: If $n=1,2,3,4,5,6,7$, 8,9 , or 10 then $R I=0,0,0.58,0.9,1.12,1.024,1.32,1.41,1.45$, or 1.49 respectively. 
The acceptable CR value should be equal or less than 0.1. Otherwise, the related pair-wise comparisons should be repeated till CR comes in the required level [35].

\subsection{Constructing the Representative Comparison Matrix of all Decision-Makers}

After constructing the comparison matrices according to each expert's opinion, aggregation is necessary to represent one comparison matrix for each level and sub-level factors. For that, the conventional AHP concepts can be employed in the FAHP environment while the AHP used geometric mean functions that satisfy the pareto principle and homogeneity condition for aggregating group decisions. If a group of $K$ decision makers make pair-wise comparisons of the importance of $n$ factors, then we get a set of $K$ comparison matrices, $\widetilde{\mathrm{A}}_{\mathrm{k}}=\left\{\tilde{\mathrm{a}}_{\mathrm{ijk}}\right\}$, where $\tilde{\mathrm{a}}_{\mathrm{ijk}}=\left(\mathrm{l}_{\mathrm{ijk}}, \mathrm{m}_{\mathrm{ijk}}, \mathrm{u}_{\mathrm{ijk}}\right)$. Therefore, the triangular fuzzy numbers in the group comparison matrix can be obtained by using the Eq. (7) - Eq. (9) [11].

$$
\begin{gathered}
\mathrm{l}_{\mathrm{ij}}=\min _{\mathrm{k}=1,2, \ldots . . \mathrm{K}}\left(\mathrm{l}_{\mathrm{ijk}}\right) \\
\mathrm{m}_{\mathrm{ij}}=\sqrt[K]{\prod_{\mathrm{k}=1}^{\mathrm{K}} \mathrm{m}_{\mathrm{ijk}}} \\
\mathrm{u}_{\mathrm{ij}}=\max _{\mathrm{k}=1,2, \ldots . \mathrm{K}}\left(\mathrm{u}_{\mathrm{ijk}}\right)
\end{gathered}
$$

\subsection{Calculating the Factor and Sub-Factor Weights}

Chang's [34] extent analysis FAHP method can be used to determine factor weights of the MCDM problems with minimum efforts. When comparing with other methods, this method needs lower computation complexity with more efficiency [34].

The steps of the Chang's method can be described as follows:

Let a fuzzy pair-wise comparison matrix be $\widetilde{\mathrm{A}}=\left(\widetilde{\mathrm{a}}_{\mathrm{ij}}\right)$ and $\tilde{\mathrm{a}}_{\mathrm{ij}}=\left(\mathrm{l}_{\mathrm{ij}}, \mathrm{m}_{\mathrm{ij}}, \mathrm{u}_{\mathrm{ij}}\right)$

Step 1. The fuzzy synthetic extent value according to the $i^{\text {th }}$ object is defined as

$$
\begin{gathered}
\mathrm{S}_{\mathrm{i}}=\sum_{\mathrm{j}=1}^{\mathrm{m}} \mathrm{M}_{\mathrm{ij}} *\left[\sum_{\mathrm{i}=1}^{\mathrm{n}} \sum_{\mathrm{j}=1}^{\mathrm{m}} \mathrm{M}_{\mathrm{ij}}\right]^{-1} \\
\sum_{\mathrm{j}=1}^{\mathrm{m}} \mathrm{M}_{\mathrm{ij}}=\left(\sum_{\mathrm{j}=1}^{\mathrm{m}} \mathrm{l}_{\mathrm{ij}}, \sum_{\mathrm{j}=1}^{\mathrm{m}} \mathrm{m}_{\mathrm{ij}}, \sum_{\mathrm{j}=1}^{\mathrm{m}} \mathrm{u}_{\mathrm{ij}}\right), \mathrm{i}=1,2, \ldots \ldots, \mathrm{n} \\
\sum_{\mathrm{i}=1}^{\mathrm{n}} \sum_{\mathrm{j}=1}^{\mathrm{m}} \mathrm{M}_{\mathrm{ij}}=\left(\sum_{\mathrm{i}=1}^{\mathrm{n}} \sum_{\mathrm{j}=1}^{\mathrm{m}} \mathrm{l}_{\mathrm{ij}}, \sum_{\mathrm{i}=1}^{\mathrm{n}} \sum_{\mathrm{j}=1}^{\mathrm{m}} \mathrm{m}_{\mathrm{ij}}, \sum_{\mathrm{i}=1}^{\mathrm{n}} \sum_{\mathrm{j}=1}^{\mathrm{m}} \mathrm{u}_{\mathrm{ij}}\right) \\
{\left[\sum_{\mathrm{i}=1}^{\mathrm{n}} \sum_{\mathrm{j}=1}^{\mathrm{m}} \mathrm{M}_{\mathrm{ij}}\right]^{-1}=\left(\frac{1}{\sum_{\mathrm{i}=1}^{\mathrm{n}} \sum_{\mathrm{j}=1}^{\mathrm{m}} \mathrm{u}_{\mathrm{ij}}}, \frac{1}{\sum_{\mathrm{i}=1}^{\mathrm{n}} \sum_{\mathrm{j}=1}^{\mathrm{m}} \mathrm{m}_{\mathrm{ij}}}, \frac{1}{\sum_{\mathrm{i}=1}^{\mathrm{n}} \sum_{\mathrm{j}=1}^{\mathrm{m}} \mathrm{i}_{\mathrm{ij}}}\right)}
\end{gathered}
$$

Step 2. The degree of possibility of $S_{j}=\left(l_{j}, m_{j}, u_{j}\right) \geq S_{i}=\left(l_{i}, m_{i}, u_{i}\right)$ is defined by comparing the values of $S_{i}$ as follows:

$$
V\left(S_{j} \geq S_{i}\right)=\operatorname{height}\left(S_{i} \cap S_{j}\right)=\left\{\begin{array}{lr}
1 & \text { if } m_{j} \geq m_{i} \\
0 & \text { if } l_{i} \geq u_{j} \\
\frac{l_{i}-u_{j}}{\left(m_{j}-u_{j}\right)-\left(m_{i}-l_{i}\right)} & \text { otherwise }
\end{array}\right.
$$

Figure 2 represents $V\left(S_{j} \geq S_{i}\right)$, for the case $m_{j}<l_{i}<u_{j}<m_{i}$, where $d$ represents the abscissa value of the highest intersection point between $S_{j}$ and $S_{i}$. Herein, the both values $V\left(S_{j} \geq S_{i}\right)$ and $V\left(S_{i} \geq S_{j}\right)$ are needed to compare $S_{i}$ and $S_{j}$.

Step 3. The minimum degree of possibility $d(i)$ of $V\left(S_{j} \geq S_{i}\right)$ for $i, j=1,2,3 \ldots, k$ can be defined as follows. 


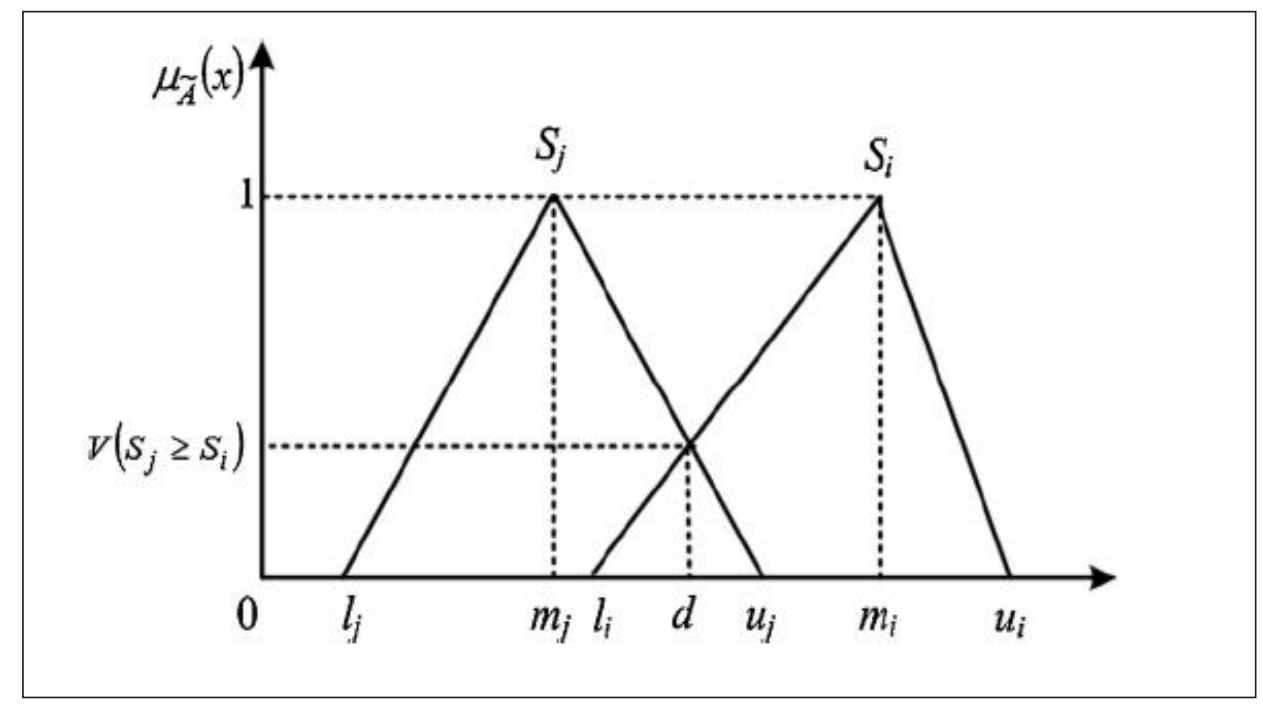

Figure 2. Intersection between $S_{j}$ and $S_{i}$

$$
\mathrm{V}\left[\left(S \geq S_{1}\right) \text { and }\left(S \geq S_{2}\right) \text { and } \ldots\left(S \geq S_{k}\right)=\min V\left(S \geq S_{i}\right), i=1,2,3, \ldots \ldots, k\right.
$$

Assume that $d\left(A_{i}\right)=\min V\left(S \geq S_{i}\right)$, for $\mathrm{i}=1,2,3, \ldots, k$. Then the weight vector is defined as:

$$
\left.W /=\left(d / A_{1}, d / A_{2}, \ldots \ldots \ldots \ldots, d / A_{n}\right)\right)^{T}
$$

where $A_{i}=1,2,3, \ldots, n$ comprises $n$ elements

Step 4. Finally, the weight vectors can be normalized as follows:

$$
W=\left(W_{1}, W_{2}, \ldots, W_{n}\right) T
$$

where $W_{1}, W_{2}, \ldots, W_{n}$ are non- fuzzy numbers .

\section{Establishing the Key Dimensions and Measuring Items Weights of a Library Website Usability Evaluation Index System}

In this section, the weights of key dimensions and measuring items for library website usability evaluation model are provided. The hierarchical structure of decision-making process was presented in Table 1. To acquire the key dimensions and measuring items weights, a pair-wise questionnaire was distributed to a group of 20 experts, including two professors of computer science, five senior lecturers of computer science, five senior assistant librarians, five web designers and three postgraduate students to get their viewpoints. The research period was January 2017 to February 2017.

The comparison matrices for each expert's assessment at the corresponding level with respect to the upper level were constructed based on their assessments on the relative importance between each pair of factors and then the representative comparison matrices for each factor were constructed by applying the geometric mean method as in Eq. (19). The resultant comparison matrices were shown in Tables 3-10.

The next step is to calculate the consistency ratio of the comparison matrices. The crisp comparison matrices allowing the decision maker's degree of confidence $(\alpha)$ as 0.5 , denotes that environmental uncertainty is steady and optimism index value $(\lambda)$ as 0.5 that expresses the attitude is fair for all the key dimensions and all measuring items were obtained using Eq. (3) and Eq. (4). Then, by employing Eq. (5) and Eq. (6), the CR value of the key dimensions comparison matrix is 0.0515 and the CR values of the comparison matrices of the measuring items within each dimension (Accessibility, Content, Efficiency, Learnability, Navigation, 


\begin{tabular}{|c|c|c|c|c|c|c|c|}
\hline & D1 & D2 & D3 & D4 & D5 & D6 & D7 \\
\hline D1 & $(1,1,1)$ & $(0.5,1.0292,3.5)$ & $(0.3333,0.6228,2)$ & $\begin{array}{l}(0.3333,0.8503 \\
1.2821)\end{array}$ & $\begin{array}{l}(0.2857,0.467, \\
0.6163)\end{array}$ & $\begin{array}{l}(0.2857,0.3586 \\
0.4373)\end{array}$ & $\begin{array}{l}(0.2857,0.4141, \\
0.5247)\end{array}$ \\
\hline D2 & $\begin{array}{l}(0.2857,0.9 \\
716,2)\end{array}$ & $(1,1,1)$ & $\begin{array}{l}(0.3333, \\
0.7402,3)\end{array}$ & $\begin{array}{l}(0.4,1.064 \\
9,3.5)\end{array}$ & $\begin{array}{l}(0.2857,0.4787 \\
0.6376)\end{array}$ & $\begin{array}{l}(0.2857,0.3651 \\
0.4472)\end{array}$ & $\begin{array}{l}(0.2857,0.4234, \\
0.54)\end{array}$ \\
\hline D3 & $\begin{array}{l}(0.5,1.6057 \\
, 3)\end{array}$ & $\begin{array}{l}(0.3333,1.3 \\
51,3)\end{array}$ & $(1,1,1)$ & $\begin{array}{l}(0.4,1.3 \\
741,3.5)\end{array}$ & $\begin{array}{l}(0.2857,0.5757 \\
0.7325)\end{array}$ & $\begin{array}{l}(0.2857,0.3586 \\
0.4373)\end{array}$ & $\begin{array}{l}(0.2857,0.4756, \\
0.5988)\end{array}$ \\
\hline D4 & $\begin{array}{l}(0.3333,1.1 \\
761,3)\end{array}$ & $\begin{array}{l}(0.2857,0.93 \\
91,2.5)\end{array}$ & $\begin{array}{l}(0.2857,0.7277 \\
2.5)\end{array}$ & $(1,1,1)$ & $\begin{array}{l}(0.2857,0.4621 \\
0.6051)\end{array}$ & $\begin{array}{l}(0.2857,0.3734 \\
0.4603)\end{array}$ & $\begin{array}{l}(0.2857,0.4141, \\
0.5247)\end{array}$ \\
\hline D5 & $(1,2.1411,3.5)$ & $\begin{array}{l}(1,2.0889 \\
3.5)\end{array}$ & $\begin{array}{l}(0.3333,1.73 \\
7,3.5)\end{array}$ & $(1,2.1638,3.5)$ & $(1,1,1)$ & $\begin{array}{l}(0.2857,0.5564 \\
0.6796)\end{array}$ & $\begin{array}{l}(0.2857,0.6683, \\
0.8185)\end{array}$ \\
\hline D6 & $(2,2.789,3.5)$ & $\begin{array}{l}(2,2.7386, \\
3.5)\end{array}$ & $\begin{array}{l}(2,2.78 \\
9,3.5)\end{array}$ & $(1.5,2.6782,3.5)$ & $\begin{array}{l}(0.2857,1.7972 \\
2.1473)\end{array}$ & $(1,1,1)$ & $\begin{array}{l}(0.3333,1.2011, \\
1.4651)\end{array}$ \\
\hline D7 & $\begin{array}{l}(1.5,2.4151 \\
, 3.5)\end{array}$ & $(1.5,2.3618,3.5)$ & $\begin{array}{l}(0.4,2.10 \\
24,3.5)\end{array}$ & $(1.5,2.4151,3.5)$ & $\begin{array}{l}(0.3333,1.4963 \\
1.8074)\end{array}$ & $\begin{array}{l}(0.3333,0.8326 \\
1.0238)\end{array}$ & $(1,1,1)$ \\
\hline
\end{tabular}

Table 3. Comparison Matrix of The Key Dimensions

\begin{tabular}{|l|l|l|l|}
\hline & D11 & D12 & D13 \\
\hline D11 & $(1,1,1)$ & $(0.3333,1.5582,3.5)$ & $(1.5,2.2772,3.5)$ \\
\hline D12 & $(0.2857,0.6418,3)$ & $(1,1,1)$ & $(0.3333,1.4823,2.5)$ \\
\hline D13 & $(0.2857,0.4391,0.6667)$ & $(0.4,0.6746,3)$ & $(1,1,1)$ \\
\hline
\end{tabular}

Table 4. Comparison matrix of the measuring items within "Accessibility (D1)"

\begin{tabular}{|l|l|l|l|}
\hline & D21 & D22 & D23 \\
\hline D21 & $(1,1,1)$ & $(0.2857,0.4124,0.6667)$ & $(0.4,1.8837,3.5)$ \\
\hline D22 & $(1.5,2.425,3.5)$ & $(1,1,1)$ & $(1.5,2.4696,3.5)$ \\
\hline D23 & $(0.2857,0.5309,2.5)$ & $(0.2857,0.4049,0.6667)$ & $(1,1,1)$ \\
\hline
\end{tabular}

Table 5. Comparison matrix of the measuring items within "Content (D2)"

\begin{tabular}{|l|l|l|}
\hline & D31 & D32 \\
\hline D31 & $(1,1,1)$ & $(0.2857,0.617,2.5)$ \\
\hline D32 & $(0.4,1.6207,3.5)$ & $(1,1,1)$ \\
\hline
\end{tabular}

Table 6. Comparison matrix of the measuring items within "Efficiency (D3)" 


\begin{tabular}{|l|l|l|l|}
\hline & D41 & D42 & D43 \\
\hline D41 & $(1,1,1)$ & $(0.2857,0.749,3)$ & $(1,2.2533,3.5)$ \\
\hline D42 & $(0.3333,1.3351,3.5)$ & $(1,1,1)$ & $(1.5,2.3714,3.5)$ \\
\hline D43 & $(0.2857,0.4438,1)$ & $(0.2857,0.4217,0.6667)$ & $(1,1,1)$ \\
\hline
\end{tabular}

Table7. Comparison matrix of the measuring items within "Learnability (D4)"

\begin{tabular}{|l|l|l|l|}
\hline & D51 & D52 & D53 \\
\hline D51 & $(1,1,1)$ & $(0.2857,0.4092,1)$ & $(0.3333,0.949,3)$ \\
\hline D52 & $(1,2.4437,3.5)$ & $(1,1,1)$ & $(0.5,1.8421,3)$ \\
\hline D53 & $(0.3333,1.0537,3)$ & $(0.3333,0.5428,2)$ & $(1,1,1)$ \\
\hline
\end{tabular}

Table 8. Comparison matrix of the measuring items within "Navigation (D5)"

\begin{tabular}{|l|l|l|l|}
\hline & D61 & D62 & D63 \\
\hline D61 & $(1,1,1)$ & $(0.2857,0.4467,1)$ & $(0.2857,0.4289,1)$ \\
\hline D62 & $(1,2.2388,3.5)$ & $(1,1,1)$ & $(0.4,1.1962,3.5)$ \\
\hline D63 & $(1,2.3315,3.5)$ & $(0.2857,0.836,2.5)$ & $(1,1,1)$ \\
\hline
\end{tabular}

Table 9. Comparison matrix of the measuring items within "Satisfaction (D6)"

\begin{tabular}{|l|l|l|l|}
\hline & $\mathrm{D} 71$ & $\mathrm{D} 72$ & $\mathrm{D} 73$ \\
\hline $\mathrm{D} 71$ & $(1,1,1)$ & $(0.5,2.0694,3.5)$ & $(0.5,1.9616,3.5)$ \\
\hline D72 & $(0.2857,0.4832,2)$ & $(1,1,1)$ & $(0.3333,0.7597,2.5)$ \\
\hline D73 & $(0.2857,0.5098,2)$ & $(0.4,1.3164,3)$ & $(1,1,1)$ \\
\hline
\end{tabular}

Table 10. Comparison matrix of the measuring items within "Usefulness (D7)"

Satisfaction and Usefulness) are $0.0110,0.0277,0.0587,0.0321,0.0180,0.0316$ and 0.0490 . The results of the comparison matrices and the representative matrices consistency test were in less than 0.1 . Thus, the consistency in each matrix is acceptable level.

After this point, the study has turned to get the key dimensions and measuring items weights by taking pair-wise comparison matrices of the key dimensions and measuring items in each dimension by applying the extent analysis fuzzy AHP method.

The fuzzy synthetic extent values of key dimensions comparison matrix were obtained using Eq. (10) - Eq. (13) and the results are as follows: 
$\mathrm{S} 1=(0.0314,0.0796,0.2894)$,

$\mathrm{S} 2=(0.0299,0.0846,0.3440)$,

$\mathrm{S} 3=(0.0321,0.1131,0.3793)$,

$\mathrm{S} 4=(0.0287,0.0855,0.3274)$,

$\mathrm{S} 5=(0.0509,0.1738,0.5101)$,

$\mathrm{S} 6=(0.0947,0.2516,0.5755)$,

$\mathrm{S} 7=(0.0682,0.2118,0.5513)$

Then the degree of possibility of $S_{j}=\left(l_{j}, m_{j}, u_{j}\right) \geq S_{i}=\left(l_{i}, m_{i}, u_{i}\right)$ was taken from individually comparing the values of $S_{i}$ as in Eq. (14) and the values of $V\left(S_{i} \geq S_{j}\right)$ shows in Table 9.

\begin{tabular}{|c|c|c|c|c|c|c|c|c|c|c|c|c|c|}
\hline $\mathrm{V}\left(\mathrm{S}_{1}>\mathrm{S}_{\mathrm{j}}\right)$ & Value & $\mathrm{V}\left(\mathrm{S}_{2}>\mathrm{S}_{\mathrm{j}}\right)$ & Value & $\mathrm{V}\left(\mathrm{S}_{3}>\mathrm{S}_{\mathrm{j}}\right)$ & Value & $\mathrm{V}\left(\mathrm{S}_{4}>\mathrm{S}_{\mathrm{j}}\right)$ & Value & $\mathrm{V}\left(\mathrm{S}_{5}>\mathrm{S}_{\mathrm{j}}\right)$ & Value & $\mathrm{V}\left(\mathrm{S}_{6}>\mathrm{S}_{\mathrm{j}}\right)$ & Value & $\mathrm{V}\left(\mathrm{S}_{7}>\mathrm{S}_{\mathrm{j}}\right)$ & Value \\
\hline $\mathrm{V}\left(\mathrm{S}_{1}>\mathrm{S}_{2}\right)$ & 0.9808 & $\mathrm{~V}\left(\mathrm{~S}_{2}>\mathrm{S}_{1}\right)$ & 1.0000 & $\mathrm{~V}\left(\mathrm{~S}_{3}>\mathrm{S}_{1}\right)$ & 1.0000 & $\mathrm{~V}\left(\mathrm{~S}_{4}>\mathrm{S}_{1}\right)$ & 1.0000 & $\mathrm{~V}\left(\mathrm{~S}_{5}>\mathrm{S}_{1}\right)$ & 1.0000 & $\mathrm{~V}\left(\mathrm{~S}_{6}>\mathrm{S}_{1}\right)$ & 1 & $\mathrm{~V}(\mathrm{~S} 7>\mathrm{S} 1)$ & 1.0000 \\
$\mathrm{~V}\left(\mathrm{~S}_{1}>\mathrm{S}_{3}\right)$ & 0.8847 & $\mathrm{~V}\left(\mathrm{~S}_{2}>\mathrm{S}_{3}\right)$ & 0.9163 & $\mathrm{~V}\left(\mathrm{~S}_{3}>\mathrm{S}_{2}\right)$ & 1.0000 & $\mathrm{~V}\left(\mathrm{~S}_{4}>\mathrm{S}_{2}\right)$ & 1.0000 & $\mathrm{~V}\left(\mathrm{~S}_{5}>\mathrm{S}_{2}\right)$ & 1.0000 & $\mathrm{~V}\left(\mathrm{~S}_{6}>\mathrm{S}_{2}\right)$ & 1 & $\mathrm{~V}(\mathrm{~S} 7>\mathrm{S} 2)$ & 1.0000 \\
$\mathrm{~V}\left(\mathrm{~S}_{1}>\mathrm{S}_{4}\right)$ & 0.9779 & $\mathrm{~V}\left(\mathrm{~S}_{2}>\mathrm{S}_{4}\right)$ & 0.9974 & $\mathrm{~V}\left(\mathrm{~S}_{3}>\mathrm{S}_{4}\right)$ & 1.0000 & $\mathrm{~V}\left(\mathrm{~S}_{4}>\mathrm{S}_{3}\right)$ & 0.9144 & $\mathrm{~V}\left(\mathrm{~S}_{5}>\mathrm{S}_{3}\right)$ & 1.0000 & $\mathrm{~V}\left(\mathrm{~S}_{6}>\mathrm{S}_{3}\right)$ & 1 & $\mathrm{~V}(\mathrm{~S} 7>\mathrm{S} 3)$ & 1.0000 \\
$\mathrm{~V}\left(\mathrm{~S}_{1}>\mathrm{S}_{5}\right)$ & 0.7168 & $\mathrm{~V}\left(\mathrm{~S}_{2}>\mathrm{S}_{5}\right)$ & 0.7668 & $\mathrm{~V}\left(\mathrm{~S}_{3}>\mathrm{S}_{5}\right)$ & 0.8441 & $\mathrm{~V}\left(\mathrm{~S}_{4}>\mathrm{S}_{5}\right)$ & 0.7579 & $\mathrm{~V}\left(\mathrm{~S}_{5}>\mathrm{S}_{4}\right)$ & 1.0000 & $\mathrm{~V}\left(\mathrm{~S}_{6}>\mathrm{S}_{4}\right)$ & 1 & $\mathrm{~V}(\mathrm{~S} 7>\mathrm{S} 4)$ & 1.0000 \\
$\mathrm{~V}\left(\mathrm{~S}_{1}>\mathrm{S}_{6}\right)$ & 0.5309 & $\mathrm{~V}\left(\mathrm{~S}_{2}>\mathrm{S}_{6}\right)$ & 0.5989 & $\mathrm{~V}\left(\mathrm{~S}_{3}>\mathrm{S}_{6}\right)$ & 0.6727 & $\mathrm{~V}\left(\mathrm{~S}_{4}>\mathrm{S}_{6}\right)$ & 0.5835 & $\mathrm{~V}\left(\mathrm{~S}_{5}>\mathrm{S}_{6}\right)$ & 0.8422 & $\mathrm{~V}\left(\mathrm{~S}_{6}>\mathrm{S}_{5}\right)$ & 1 & $\mathrm{~V}(\mathrm{~S} 7>\mathrm{S} 5)$ & 1.0000 \\
$\mathrm{~V}\left(\mathrm{~S}_{1}>\mathrm{S}_{7}\right)$ & 0.6258 & $\mathrm{~V}\left(\mathrm{~S}_{2}>\mathrm{S}_{7}\right)$ & 0.6844 & $\mathrm{~V}\left(\mathrm{~S}_{3}>\mathrm{S}_{7}\right)$ & 0.7591 & $\mathrm{~V}\left(\mathrm{~S}_{4}>\mathrm{S}_{7}\right)$ & 0.6723 & $\mathrm{~V}\left(\mathrm{~S}_{5}>\mathrm{S}_{7}\right)$ & 0.9207 & $\mathrm{~V}\left(\mathrm{~S}_{6}>\mathrm{S}_{7}\right)$ & 1 & $\mathrm{~V}(\mathrm{~S} 7>\mathrm{S} 6)$ & 0.9199 \\
\hline
\end{tabular}

Table 11. Values of $V\left(S_{i} \geq S_{j}\right)$

The minimum degree of possibility $d / i$ of $\mathrm{V}\left(S_{i} \geq S_{j}\right)$ for $i, j=1,2, \ldots, 7$ was found by using Eq. (15) and the weight vector $(W /)$ was calculated from Eq. (16).

$$
W /=(0.5309,0.5989,0.6727,0.5835,0.8422,1,0.9199)
$$

Finally, the relative weights of the seven dimensions were obtained from normalizing the weight vector using Eq. (17).

$$
W=\left(W_{D 1}, W_{D 2}, W_{D 3^{3}}, W_{D 4^{4}} W_{D 5^{5}}, W_{D 6^{6}}, W_{D 7}\right)=(0.1031,0.1163,0.1307,0.1133,0.1636,0.1942,0.1787)
$$

The dimension "Satisfaction (D6)" plays the most important part (19.42\%) in library website usability, followed by "Usefulness (D7)".

The relative weight vectors of the measuring items within each dimension were determined following the above similar calculation and Table 12 summarizes the normalized weight vectors of the key dimensions and measuring items for library website usability evaluation index system.

Table 12 Weight vectors of the key dimensions and measuring items

\section{Discussion}

Active presence of libraries on the internet has helped libraries to move one step ahead in the Internet era in order to serve their 


\begin{tabular}{|c|c|c|c|}
\hline Dimension & $\begin{array}{l}\text { Weights of } \\
\text { Dimension }\end{array}$ & $\begin{array}{l}\text { Measuring } \\
\text { Item }\end{array}$ & $\begin{array}{l}\text { Weights of } \\
\text { Measuring } \\
\text { Item }\end{array}$ \\
\hline $\begin{array}{l}\text { Accessibility } \\
\left(D_{1}\right)\end{array}$ & 0.1031 & $\begin{array}{l}\text { D11 } \\
\text { D12 } \\
\text { D13 }\end{array}$ & $\begin{array}{l}0.3942 \\
0.3322 \\
0.2735\end{array}$ \\
\hline Content $\left(\mathrm{D}_{2}\right)$ & 0.1163 & $\begin{array}{l}\text { D21 } \\
\text { D22 } \\
\text { D23 }\end{array}$ & $\begin{array}{l}0.3110 \\
0.4620 \\
0.2269\end{array}$ \\
\hline $\begin{array}{l}\text { Efficiency } \\
\left(\mathrm{D}_{3}\right)\end{array}$ & 0.1307 & $\begin{array}{l}\text { D31 } \\
\text { D32 }\end{array}$ & $\begin{array}{l}0.4525 \\
0.5475\end{array}$ \\
\hline $\begin{array}{l}\text { Learnability } \\
\left(\mathrm{D}_{4}\right)\end{array}$ & 0.1133 & $\begin{array}{l}\text { D41 } \\
\text { D42 } \\
\text { D43 }\end{array}$ & $\begin{array}{l}0.3881 \\
0.4150 \\
0.1969\end{array}$ \\
\hline $\begin{array}{l}\text { Navigation } \\
\left(D_{5}\right)\end{array}$ & 0.1636 & $\begin{array}{l}\text { D51 } \\
\text { D52 } \\
\text { D53 }\end{array}$ & $\begin{array}{l}0.2281 \\
0.4012 \\
0.3107\end{array}$ \\
\hline $\begin{array}{l}\text { Satisfaction } \\
\left(D_{6}\right)\end{array}$ & 0.1942 & $\begin{array}{l}\text { D61 } \\
\text { D62 } \\
\text { D63 }\end{array}$ & $\begin{array}{l}0.1152 \\
0.4480 \\
0.4367\end{array}$ \\
\hline $\begin{array}{l}\text { Usefulness } \\
\left(D_{7}\right)\end{array}$ & 0.1787 & $\begin{array}{l}\text { D71 } \\
\text { D72 } \\
\text { D73 }\end{array}$ & $\begin{array}{l}0.3851 \\
0.2973 \\
0.3177\end{array}$ \\
\hline
\end{tabular}

Table 12. Weight vectors of the key dimensions and measuring items

users with global resources and services for study, reference and research. This shows a growing trend to be at par with the best libraries in the world. Developing a usable and effective library website is challenging task to success, maintaining and redesigning a website to meet the constantly changing user needs is a seemingly impossible task. Thus usability testing is expected to achieve this task as it not only supports identifying interface problems but also helps developing ways and means that would solve those problems. The available literature is attested that there is no any fixed criterion for usability evaluation process because many of the prior researches had discussed it in different aspects. In addition, heuristic evaluation methods, user surveys, and user observations were also used to evaluate the usability of library websites as well as different type and number of usability dimensions was undertaken for measurement development.

We have identified and validated a major measurement instrument dimensions and their measurement items for usability evaluation specific to library websites in Sri Lanka from our previous study. This study attempted to assess and prioritize relative weightings of the key dimensions and measuring items to ensure successful implementation of library website usability index system. Herein, the FAHP technique was used to determine the relative importance weights of the usability dimensions and measuring items. The process consists of four successive stages: an empirical data collection stage where a committee of experts in the internet and information technology sector filled in pair-wise comparisons of the importance of the key dimensions and all measuring items at the corresponding level with respect to the upper level dimensions with the help of questionnaires. In the comparison stage, the fuzzy comparison matrices of experts at the corresponding levels were build. At the validation stage, the consistencies of the pair-wise comparison matrices were measured to assure a certain quality level of a decision. Finally, a computation stage where a FAHP approach based on the extent analysis method was used to get the key dimensions and measuring items weights. 
The overall perceived weightings of the seven dimensions of library website usability evaluation are presented in Figure 3. According to the results, the usability dimension of satisfaction is regarded as the most important with $19.42 \%$ in comparison with the rest of dimensions. This shows that the system should be pleasant to use, so that users are subjectively satisfied when using it. However, the accessibility was regarded as the least important dimension.

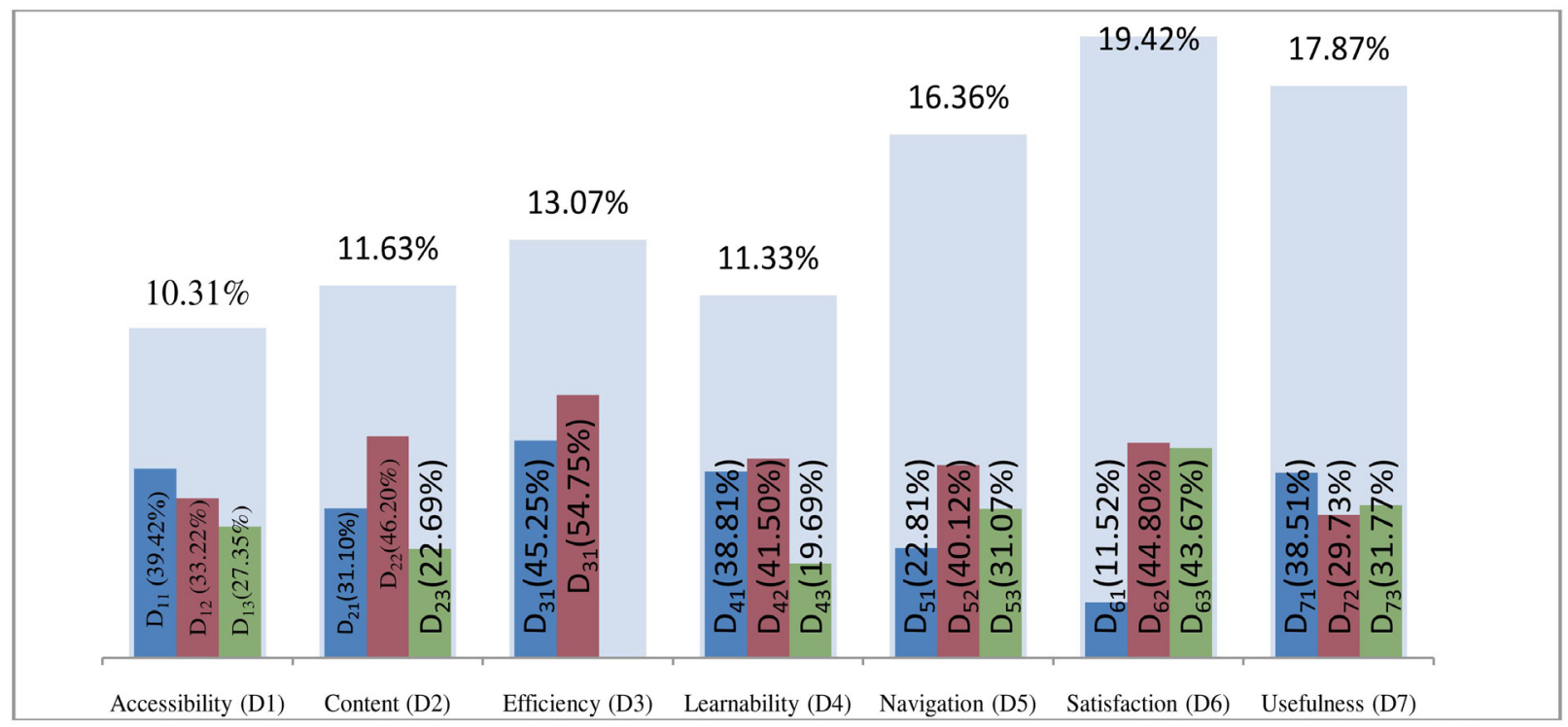

Figure 3. Overall perceived weightings of the dimensions and measurement items of library website usability evaluation model

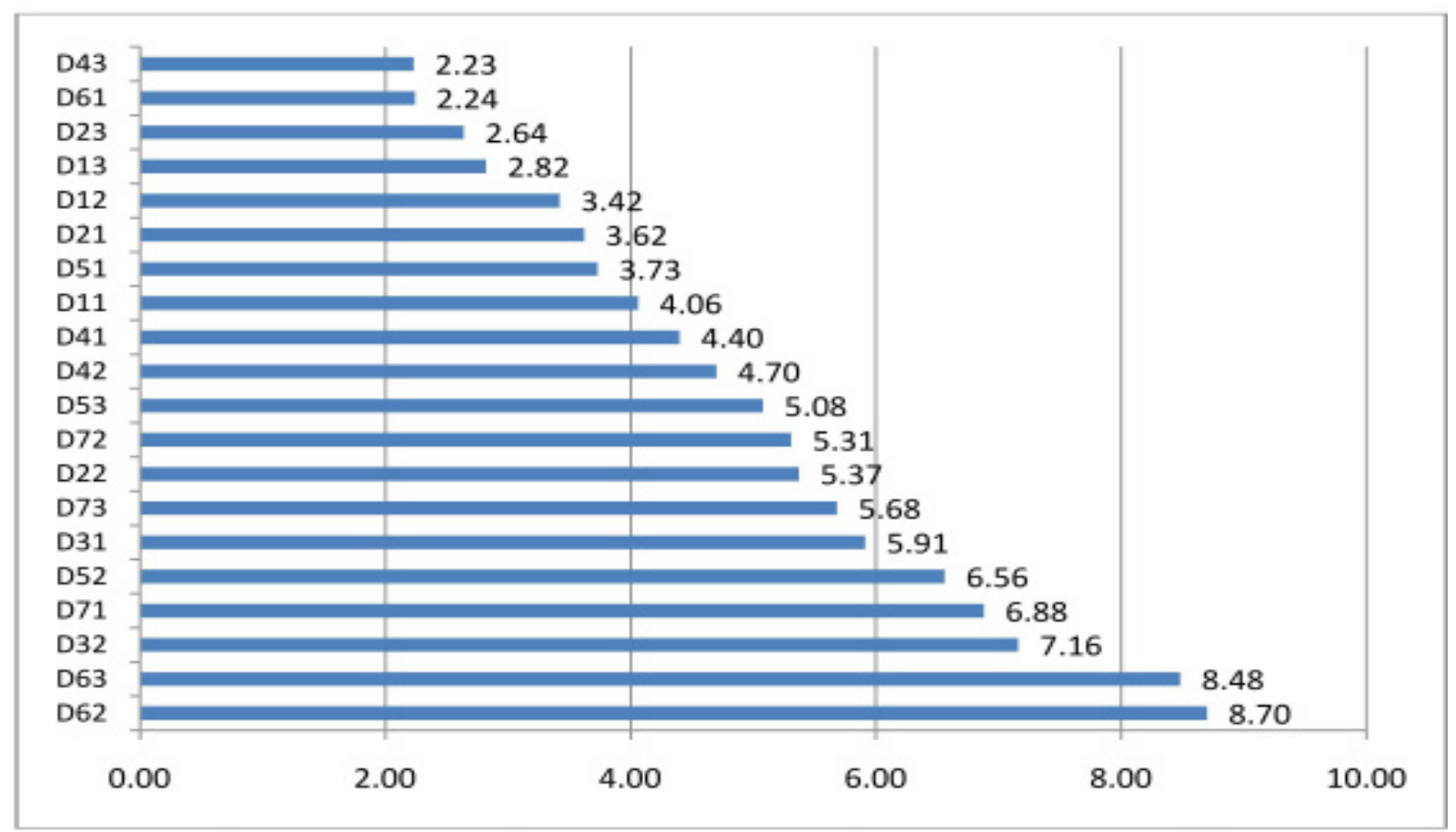

Figure 4. Cumulative contribution of measurement items of dimensions of library website usability evaluation model

Figure 4 illustrates the cumulative contribution of measurement items of dimensions of library website usability in decisionmaking at the second level in descending order of importance. According to the results as presented, the top 7 of the 20 measurement items assessed accounted for 49.37 percent of importance in their decision-making process. First two ranks belong 
to the usability dimension of satisfaction. Meanwhile, ranked third and sixth is the usability dimension of efficiency and ranked fourth and seventh is the usability dimension of usefulness.

Furthermore, the results of the study provide a strong contribution to design a library website and further evidence that website usability, as related to its design, is an important factor in the user's intention to use of the website while the motivation of the study was to better understand of relational importance of website usability dimensions and its role in a user's acceptance level of a website. Libraries can revise their websites according to the most important dimensions of web usability and then can increase volume of user transactions to the website. Website usability measuring instrument allows librarians to establish standards by evaluating the usability level of their websites and compare them with their relatives. Therefore, employing valid and reliable research instruments to measure website usability is vital for both staff and users of libraries. Finally, Forrester's research [38] has found that 50 percent of potential attraction of website can lose if users cannot find what they are searching for while when users' first experience is unsuccessful, then 40 percent of users do not revisit the website again.

\section{Conclusion}

A significant understanding of awareness and willingness of users cannot be done without a proper investigation of website usability while usability evaluation is a useful tool to keep up the quality of websites. The present study aimed to confer with our previous study that have identified and validated a major measurement instrument dimensions and their measurement items for usability evaluation specific to a library websites in Sri Lanka in order to ascertain and prioritize relative weightings of the key dimensions and measuring items to ensure successful implementation of library website usability index system with reasonable and objective factor weights. The immediate goal of this study was to investigate the perception on the priority of the key dimensions and measuring items from the viewpoint of experts. Based on the obtained results, the perceived relative importance weights of seven dimensions together with 20 measuring items were determined using the extent analysis fuzzy AHP technique.

The main contribution of this study is that it leads a technique for calculating the relative importance of dimensions and measuring items influencing library website usability by scientifically comparing with each other. The technique has capabilities to perform effective results with easy computations than the experts' assignation of the absolute priorities of each factor. Furthermore, the study used fuzzy multi-criteria evaluation methodology under a fuzzy environment to avoid uncertainty, ambiguity and loss of data, and difficulties faced in assessment cycle while all pair-wise comparisons which are in linguistic scale were converted into triangular fuzzy numbers for making uniform consensus of the decision makers. The findings of this study can be considered as indicators that provide necessary information about priority listing of dimensions for the web designers to design library websites more systematically and effectively. Therefore, the results of this study can be of benefit to the libraries that are trying to implement or improve quality of their websites because recognition of the user's priorities may reveal critical areas leading to the development of a more effective user-oriented website. In the next phase of this research, the authors plan to continue working with the obtained relative weightings of the key dimensions and measuring items to develop a library website usability evaluation framework based on the combination of fuzzy AHP and comprehensive evaluation method.

\section{Acknowledgement}

The authors would like to convey their sincere gratitude to all those who have significantly contributed towards the completion of this research paper.

\section{References}

[1] Babu, B. R., Jeyshankar, R., Rao, P. N. (2010). Websites of Central Universities in India : A Webometric Analysis, DESIDOC J. Libr. Inf. Technol., 30 (4) 33-43.

[2] Shadpour, P., Teimourpour, B., Asadi, R. (2013). Webometrics-based Analysis and Ranking of Iranian Hospital Websites, Int J Hosp Res, 2, (2) 77-84.

[3] Pant, A. (2015). Usability evaluation of an academic library website, Electron. Libr., 33 (5) 896-915.

[4] Lee,Y., Kozar, K. A. (2012). Understanding of website usability: Specifying and measuring constructs and their relationships, Decis. Support Syst., 52 (2) 450-463. 
[5] Nielsen, J. (2012). Usability 101: Introduction to Usability, 2012. [Online]. Available: https://www.nngroup.com/articles/ usability-101-introduction-to-usability/.

[6] Becker, S. A., Mottay, F. E. (2001). A global perspective on web site usability, IEEE Softw., 18 (1) 54-61.

[7] Nagpal, R., Mehrotra, D., Kumar Bhatia, P., Sharma, A. (2015). Rank University Websites Using Fuzzy AHP and Fuzzy TOPSIS Approach on Usability," Int. J. Inf. Eng. Electron. Bus., 7 (1) 29-36.

[8] Chang, C. W., Wu, C. R., Lin, H. L. (2008). Integrating fuzzy theory and hierarchy concepts to evaluate software quality, Softw. Qual. J., 16(2) 263-276.

[9] Nagpal, R., Mehrotra, D., Bhatia, P. K., Sharma, A. (2015). FAHP Approach to Rank Educational Websites on Usability, Int. J. Comput. Digit. Syst., 4 (4) 251-260.

[10] Sadeghi, M. (2012). Using analytic network process in a group decision-making for supplier selection, Informatica, 23 (4) $621-643$.

[11] Chen, J.-F., Hsieh, H.-N., Do, Q. H. (2015). Evaluating teaching performance based on fuzzy AHP and comprehensive evaluation approach, Appl. Soft Comput., 28. 100-108.

[12] Mikhailov, L., Tsvetinov, P. (2004). Evaluation of services using a fuzzy analytic hierarchy process, Appl. Soft Comput. J., 5 (1) 23-33.

[13] Güngör, Z., Serhadl1olu, G., Kesen, S. E. (2009). A fuzzy AHP approach to personnel selection problem, Appl. Soft Comput., $9(2) 641-646$.

[14] Pandey, A., Kumar, A. A. (2017). Commentary on ? Evaluating the criteria for human resource for science and technology (HRST) based on an integrated fuzzy AHP and fuzzy DEMATEL approach???. Appl. Soft Comput. J., 51 (1) 351-352.

[15] Taylan, O., Bafail, A. O., Abdulaal, R. M. S., Kabli, M. R. (2014). Construction projects selection and risk assessment by fuzzy AHP and fuzzy TOPSIS methodologies, Appl. Soft Comput. J., 17, p.105-116.

[16] Sadeghi, M. (2013). Identifying and prioritizing of effective constructs in readiness of knowledge management implementation by using fuzzy analytic hierarchy process (AHP), J. Knowl. Manag., 5 (1) 16-31.

[17] Mehralian, G., Nazari, J. A., Rasekh, H. R., Hosseini, S. (2016). TOPSIS approach to prioritize critical success factors of TQM, $T Q M J ., 28(2)$ 235-249.

[18] Moghimi, V., Jusan, M. B. M. (2015). Priority of structural housing attribute preferences: identifying customer perception, Int. J. Hous. Mark. Anal., 8 (1) 36-52.

[19] Liu, H., Xuan, W., Cui, X. (2015). Determine weights of evaluation indices for E-Commerce websites ranking based on fuzzy AHP, Electron. Eng. Informat. Sci., 2006, p. 271-274.

[20] Atalay, K. D., Eraslan, E. (2012). Multi-criteria Usability Evaluation of Electronic Devices in a Fuzzy Environment, Hum. Factors Ergon. Manuf. Serv. Ind., p. 1-12.

[21] Pearson, J. M., Pearson, A., Green, D. (2007). Determining the importance of key criteria in web usability, Manag. Res. News, $30(11) 816-828$.

[22] Calisir, F., Elvan Bayraktarolu, A., Altin Gumussoy, C., 0lker Topcu, Y., Mutlu, T. (2010). The relative importance of usability and functionality factors for online auction and shopping web sites, Online Inf. Rev., 34 (3) 420-439.

[23] Mustafa, M., Kamal., Alsudairi, M. (2009). Investigating the importance of factors influencing integration technologies adoption in local government authorities, 3 (3).

[24] Roy, S., Pattnaik, P. K., Mall, R. (2017). Quality assurance of academic websites using usability testing: an experimental study with AHP," Int. J. Syst. Assur. Eng. Manag., 8 (1) 1-11.

[25] Singer, D. (1990). A fuzzy set approach to fault tree and reliability analysis, Fuzzy Sets Syst., 34 (2) 145-155.

[26] Lai, C.-F., Chiu, P.-S., Huang, Y.-M., Chen, T.-S., Huang, T.-C. (2014). An evaluation model for digital libraries' user interfaces using fuzzy AHP," Electron. Libr., 32 (1) 83-95. 
[27] Van Laarhoven, P. J. M., Pedrycz, W. (). A Fuzzy Extension of Saaty’s Priority Theory, Fuzzy Sets Syst., 11, p. 229-241, 983.

[28] Buckley, J. J. (1985). Fuzzy hierarchical analysis, Fuzzy Sets Syst., 17 (3) 233-247.

[29] Dominic, P. D. D., Khan, H. (2014). Performance Measure of Airline Websites Using Analytical Hierarchy Process \& Fuzzy Analytical Hierarchy Process, In International Conference on Control System, Computing and Engineering, 2014, November, $p$ 28-30.

[27] Hepu Deng. (1999). Multicriteria analysis with fuzzy pairwise comparison, In: FUZZ-IEEE’99. 1999 IEEE Int. Fuzzy Syst. Conf. Proc. (Cat. No.99CH36315), 21, p. 726-731 vol.2.

[28] Dubois, D., Prade, H. (1980). Fuzzy Sets Systems: Theory and Applications. New York: Academic Press.

[29] Zadeh, L. A. (1975). The concept of a linguistic variable and its application to approximate reasoning-I, Inf. Sci. (Ny), 8 (3) 199249 .

[30] Kahraman, C., Ertay, T., Büyüközkan, G. (2006). A fuzzy optimization model for QFD planning process using analytic network approach, Eur. J. Oper. Res., 171 (2) 390-411.

[31] Chang, D.-Y. (1996). Applications of the extent analysis method on fuzzy AHP, Eur. J. Oper. Res., 95 (3) 649-655.

[32] Saaty, T. L. (1990). How to make a decision: The analytic hierarchy process, Eur. J. Oper. Res., 48 (1) 9-26.

[33] Ayað, Z. (2014). A fuzzy analytic hierarchy process tool to evaluate computer-aided manufacturing software alternatives, Turkish J. Fuzzy Syst., 5 (2) 114-127.

[34] Awad, M. R., Nazmy, P. T., Ismael, P., Ismael, A. (2013). Integrating Approach For Multi Criteria Decision Making ( Case Study/ : Ranking For Bulk Carrier Shipbuilding Region ), Int. J. Sci. Technol. Res., 2 (10) 20-28.

[35] Forrester. (1999). Website Usability. 